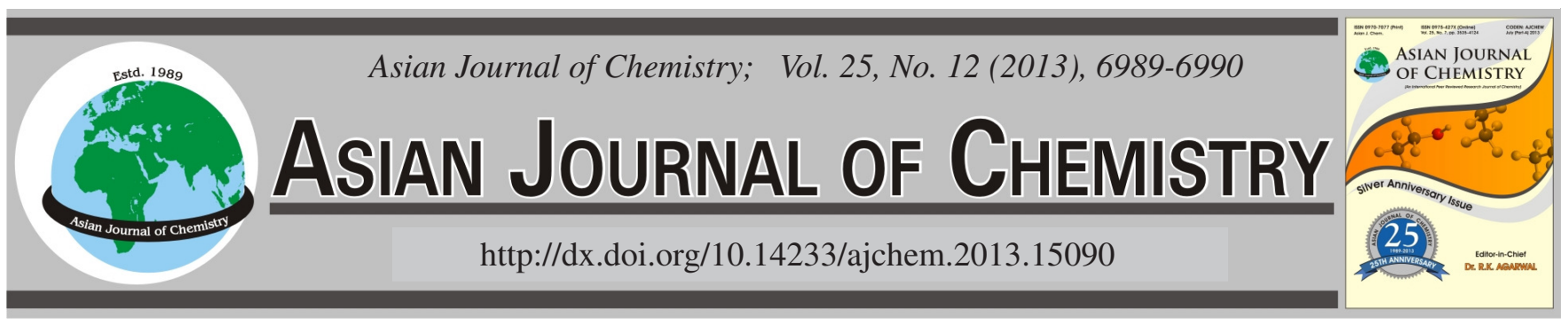

NOTE

\title{
Chemotaxonomic Significance of Oregonin in Alnus Species
}

\section{S.E. CHOI}

Department of Cosmetology Science, Nambu University, Gwangju City 506-706, Republic of Korea

Corresponding author: Fax: +82 62 4431232; Tel: +82 62 9700210; E-mail: sechoi@ nambu.ac.kr

A diarylheptanoid, (5S)-1,7-bis-(3,4-dihydroxyphenyl)-5-hydroxyheptane-3-on-5-O- $\beta$-D-xyiopyranoside, named as oregonin (1), was isolated from the bark of Alnus pendula Matsumura which is a species of the genus Alnus species, growing throughout Korea. The structure elucidation was accomplished by various spectroscopic methods including negative FAB-MS, ${ }^{1} \mathrm{H}$ NMR and ${ }^{13} \mathrm{C}$ NMR techniques or comparison with authentic samples.

Key Words: Alnus pendula, Betulaceae, Diarylheptanoid, Chemotaxonomy.

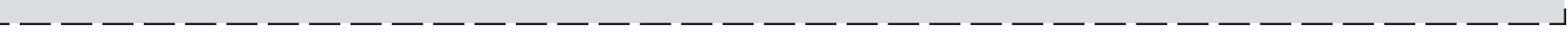

Genus Alnus refers to deciduous broad-leaved trees or shrubs found in damp areas and mountains and comprises of more than 17 species, Alnus borealis Koidzumi, Alnus firma Sieb. et Zucc., Alnus hirtella Koidz., Alnus hirsuta Turcz, Alnus hirsuta Turcz. var. sibirica Fischer, Alnus japonica Steudel, Alnus maritima var. arguta Regel., Alnus japonica Thunb. var. koreana Callier, Alnus japonica Thunb. var. reginosa Nakai, Alnus japonica Thunb. var. serrata Nakai, Alnus mandshurica Callier, Alnus mandschurica Thunb. for. barbinervis, Alnus mandschurica Thunb. for. pubescens Kitagawa, Alnus maximowiczii Call, Alnus mayrii Call, Alnus pendula Matsum, Alnus vermicularis Nakai are growing in Korea ${ }^{1}$. The bark of Alnus pendula (bar code; PB 2368.2) as well as MeOH extracts of Alnus pendula (leaf, bar code; PB 2368.1), Alnus firma (fruit, stem, leaf, flower, bar code; PB 2366.1-4) and Alnus maximowiczii (flower, bark, leaf, bar code; PB 2364.1-3) were purchased from the Korea Plant Extract Bank in October 2008.

Diarylheptanoids are characteristic components of the Alnus species ${ }^{2,3}$. Several interesting biological activities of diarylheptanoids including their antiinflammatory ${ }^{4-7}$ and antioxidant properties ${ }^{8}$ have previously been reported. In a previous study conducted in our lab, quantitative analysis of diarylheptanoids including oregonin (1) was conducted using HPLC on Alnus japonica, Alnus hirsuta and Alnus hirsuta var. sibirica ${ }^{9}$. Here, as part of our continuous search for diarylheptanoids from new natural sources, we describe the isolation and identification of oregonin (1) from the bark of Alnus pendula and screening of oregonin (1) from some other
Alnus species [Alnus firma (fruit, stem, leaf, flower) and Alnus maximowiczii (flower, bark, leaf)].<smiles>[M]OC(CCc1ccc(O)c(O)c1)CC(=O)CCc1ccc(O)c(O)c1</smiles>

Chemical structures of compound $\mathbf{1}$ isolated from Alnus pendula Matsumura

Extraction and isolation: The dried and powdered bark (300 g) of Alnus pendula was extracted using $80 \%$ aqueous acetone at room temperature for 3 days. The filtrate was concentrated and applied to a Sephadex LH-20 column (25-100 $\mu \mathrm{m}$, $8 \times 150 \mathrm{~cm}$, Pharmacia, Uppsala, Sweden) containing increasing proportions of $\mathrm{MeOH}$ (60-100\%) afforded 5 fractions (1-5). Repeated column chromatography of fraction 2 on the $\mathrm{MCl}-$ Gel CHP 20P (75-150 $\mu \mathrm{m}, 5 \times 80 \mathrm{~cm}$, Mitsubishi Chemical Co., Tokyo, Japan) and then fraction 2-2 on Disogel (40-60 $\mu \mathrm{m}, 3 \times 50 \mathrm{~cm}$, Daiso CO., Osaka, Japan) with 30-80 \% methanol gradient in middle pressure liquid chromatography (MPLC) system $(5 \mathrm{~mL} / \mathrm{min}, 280 \mathrm{~nm})$ resulted in oregonin (1).

Oregonin (1): Brown amorphous powder, Negative FAB MS: m/z 477 [M-H] $]^{-}{ }^{1} \mathrm{H}$ NMR $\left(600 \mathrm{MHz}, \mathrm{DMSO}-d_{6}+\mathrm{D}_{2} \mathrm{O}\right)$ : $\delta$ 6.67-6.60 (4H in total, H-2', 2", 5',5"), 6.48-6.45 (2H in total, H-6", 6'), 4.19 (1H, br d, J = 7.8 Hz, xyl-1), 4.03 (1H, m, H-5), $3.76(1 \mathrm{H}, \mathrm{dd}, J=11.4,6 \mathrm{~Hz}$ xyl-5e $), 3.35(1 \mathrm{H}, \mathrm{m}, \mathrm{xyl}-4), 3.08-$ $2.56(8 \mathrm{H}$ in total, $\mathrm{H}-1,2,4,7), 1.74-1.68$ (2H in total, $\mathrm{m}, \mathrm{H}-6)^{10-12}$. ${ }^{13} \mathrm{C}$ NMR $\left(150 \mathrm{MHz}\right.$, DMSO- $\left.d_{6}+\mathrm{D}_{2} \mathrm{O}\right)(\text { Table- } 1)^{10-12}$. 


\begin{tabular}{cc|cc}
\hline \multicolumn{4}{|c}{ TABLE-1 } \\
\hline \multicolumn{4}{|c}{${ }^{13}$ C NMR SPECTRA OF COMPOUND 1 } \\
\hline Carbon No. & Compound 1 & Carbon No. & Compound 1 \\
\hline C-1 & 28.7 & C-3" & 145.1 \\
C-2 & 45.1 & C-4' & 143.2 \\
C-3 & 209.6 & C-4" & 143.4 \\
C-4 & 47.5 & C-5' & 116.0 \\
C-5 & 76.9 & C-5" & 116.0 \\
C-6 & 39.7 & C-6' & 119.2 \\
C-7 & 30.5 & C-6" & 119.3 \\
C-1' & 132.4 & Xyl-1 & 102.8 \\
C-1" & 133.3 & Xyl-2 & 74.7 \\
C-2' & 115.8 & Xyl-3 & 77.0 \\
C-2" & 115.8 & Xyl-4 & 69.8 \\
C-3' & 145.1 & Xyl-5 & 66.0 \\
\hline *150 MHz (DMSO- $\left.d_{6}+\mathrm{D}_{2} \mathrm{O}\right)$ & &
\end{tabular}

Quantitative analysis of oregonin (1) of Alnus pendula using high pressure liquid chromatography (HPLC): HPLC was used for the quantitative analysis of the oregonin (1) contents. An Waters 600 series HPLC system (Milford, MA, USA), was employed and equipped with a vacuum degasser, a binary pump, a UV detector and column compartment. Oregonin (1) was separated on Kromasil 100-5 C18 $(4.6 \times 250$ mm, $5 \mu \mathrm{m}$ particle) with an linear gradient water:acetonitrile $=90: 10$ to 60:40 for $24 \mathrm{~min}$. The column temperature was maintained at room temperature and the flow rate was $1.0 \mathrm{~mL} / \mathrm{min}$. The system was monitored at $280 \mathrm{~nm}\left(\lambda_{\max }\right.$ of 1) eluting at $19.09 \mathrm{~min}$. Oregonin (1) was detected in the extracts of only the bark of Alnus pendula but not in the leaf extracts of Alnus pendula, as well as the extracts of Alnus firma (fruit, stem, leaf, flower) and Alnus maximowiczii (flower, bark, leaf). We were able to quantify oregonin (1) from the bark extract of Alnus pendula $(7.69 \pm 0.079 \%)$ using a calibration equation $(\mathrm{y}=5201.9 \mathrm{x}-$ 47967; $\mathrm{R}^{2}=0.9985$ ).

Chemotaxonomic significance: This is report on the isolation and identification of oregonin (1) from Alnus pendula.
Since the initial isolation of oregonin (1) from Alnus rubra ${ }^{13}$ and oregonin (1) has only been distributed among Alnus hirsuta ${ }^{3}$, Alnus cordata, Alnus incana, Alnus virdis and Alnus glutinosa $^{14}$, Alnus japonica ${ }^{15}$, Alnus serrulatoides ${ }^{11,12}$ and Pinus flexilis $^{10}$.

\section{ACKNOWLEDGEMENTS}

This work was supported by the National Research Foundation of Korea Grant funded by the Korean Government (Ministry of Education) [NRF-2010-355-E00067] and this study was supported (in part) by research funds from Nambu University, 2013.

\section{REFERENCES}

1. W.T. Lee, Lineamenta Florae Koreae, Academy Press, Vol. 1, p. 154 (1996).

2. Y. Asakawa, Bull. Chem. Soc. Jpn., 44, 2761 (1971).

3. M.W. Lee, T. Tanaka, G.I. Nonaka and I. Nishioka, Phytochemistry, 31, 2835 (1992).

4. M.W. Lee, N.Y. Kim, M.S. Park, K.H. Ahn, S.H. Toh, D.R. Hahn, Y.C. Kim and H.T. Chung, Planta Med., 66, 551 (2000).

5. M.W. Lee, J.H. Kim, D.W. Jeong, K.H. Ahn, S.H. Toh and Y.J. Surh, Biol. Pharm. Bull., 23, 517 (2000).

6. J.M. Han, W.S. Lee, J.R. Kim, J.S. Son, K.H. Nam, S.C. Choi, J.S. Lim and T.S. Jeong, J. Agric. Food Chem., 55, 9457 (2007).

7. J.M. Han, W.S. Lee, J.R. Kim, J.S. Son, O.H. Kwon, H.J. Lee, J.J. Lee and T.S. Jeong, J. Agric. Food Chem., 56, 92 (2008).

8. Y.A. Lee, D.W. Jeong, K.H. Kim, J.S. Kim, S.W. Kim and M.W. Lee, Yakhak Hoeji, 47, 193 (2000).

9. H.W. Lim, M.K. Kim, H.J. Kim, J.G. Shim, G.H. Kim, H.K. Choi and M.W. Lee, Korean J. Pharmacog., 35, 384 (2004).

10. K.K. Lee, B.D. Bahler, G.A. Hofman, M.R. Mattern, R.K. Johnson and D.G.I. Kingston, J. Nat. Prod., 61, 1407 (1998)

11. S. Ohta, T. Aoki, T. Hirata and T. Suga, J. Chem. Soc., 1, 1635 (1984).

12. T. Suga, S. Ohta, T. Hirata and T. Aoki, Chem. Lett., 895 (1982).

13. J.J. Karchesy, M.L. Laver, D.F. Barofsky and E. Barofsky, Chem. Commun., 649 (1974).

14. N.R. Guz, P. Lorenz and J.P. Metraux, Biochem. Syst., 30, 471 (2002).

15. T. Aoki, S. Otha and T. Suga, Phytochemistry, 29, 3611 (1990). 